\title{
IMPLEMENTASI PROGRAM SANITASI AUSTRALIA INDONESIA \\ INFRASTRUCTURE GRANTS FOR SANITATION/SAIIG DI KOTA \\ CIMAHI JAWA BARAT PADA TAHUN 2020-2021
}

\author{
Yusep Ginanjar ${ }^{1}$, I Wayan Aditya Harikesa ${ }^{2}$ \\ Universitas Jenderal Achmad Yani \\ Email : yusep.ginanjar@lecture.unjani.ac.id
}

\begin{abstract}
Abstrak
Sesuai dengan tujuan Millenium Development Goals (MDGs) dari United Nation nomor sekian tentang "Air Minum dan Sanitasi", Pemerintah Kota Cimahi melakukan kerjasama dengan Pihak Australia untuk mengimplementasikan pengadaan air bersih yang lebih terstruktur. Kerja sama yang dilakukan oleh kedua pihak ini disebut dengan Infrastructure Grants For Sanitation meliputi drainase, pembangunan sektor limbah, dan juga pentahapan sistem air limbah domestik. Dengan adanya pengimplementasian pengadaan air bersih ini diharapkan dapat meningkatkan kesejahteraan hidup masyarakat di Kota Cimahi.
\end{abstract}

Kata Kunci : Sanitasi, Kerja sama, SAAIG, Cimahi

\begin{abstract}
In accordance with the Millennium Development Goals (MDGs) of the United Nations number and the number about "Drinking Water and Sanitation", the City Government of Cimahi collaborated with the Australian Party to implement a more structured clean water supply. The cooperation carried out by the two parties is called the Infrastructure Grants For Sanitation covering drainage, construction of the waste sector, as well as the phasing of the domestic wastewater system. With the implementation of the provision of clean water, it is hoped that it can improve the welfare of the community in Cimahi City.
\end{abstract}

Keywords : Sanitation, Cooperation, SAAIG, Cimahi.

\section{PENDAHULUAN}

Melalui program global MDGs secara nasional telah disepakati bahwa pemerintah menetapkan target akses terhadap sanitasi sebesar $62,4 \%$ yang harus tercapai di Tahun 2014. Pada perkembangannya hingga tahun 2015, secara nasional capaian prosentase tersebut baru mencapai 60,5\%, dari base line di tahun 
2009 sebesar 51,2\%. Walaupun belum mencapai sasaran, fenomena tersebut menunjukan adanya percepatan pembangunan sanitasi secara sungguh-sungguh dan melibatkan seluruh lapisan pemerintahan untuk mengejar ketertinggalan Indonesia. Salah satu upaya ini adalah dengan dicanangkannya Program Percepatan Pembangunan Sanitasi Permukiman (PPSP) yang bertujuan untuk menggutamakan pembangunan sanitasi di daerah.

Berdasarkan hal tersebut, pemerintah Kota Cimahi telah memiliki modal yang cukup kuat untuk memperkuat target nasional. Sejak tahun 2011, Kota Cimahi mengikuti PPSP untuk pelaksanaan program Percepatan Pembangunan Sanitasi Permukiman. Pemerintah Kota Cimahi telah membentuk Pokja Air Minum dan Penyehatan Lingkungan (AMPL) melalui Keputusan Walikota Cimahi nomor : 050/Kep401-Bappeda/2010 tanggal 13 Desember 2010 yang diperbaharui melalui Keputusan Walikota nomor : 690/Kep121-Bappeda/2011 tanggal 24 Februari 2011. Pokja AMPL ini bertugas antara lain Menyusun buku putih sanitasi, membuat rencana strategis sanitasi, membuat rencana aksi sanitasi, informasi mengenai kegiatan-kegiatan sanitasi (project digest), penetapan prioritas dan zonasi (priority setting and sanitation zoning), dan tugas-tugas lain dalam rangka pembangunan sanitasi Kota Cimahi. Pada tahun 2011 POKJA AMPL Kota Cimahi telah menyusun Buku Putih Sanitasi, buku laporan studi Environmental Health Risk Assesment (EHRA), buku laporan Studi Pemberdayaan Masyarakat, Jender, dan Kemiskinan (PMJK), buku laporan Studi Layanan Sanitasi (SSA), buku laporan Studi Komunikasi dan Media, serta hasil penetapan prioritas dan zonasi sanitasi yang berisi hasil pengkajian dan pemetaan sanitasi. Lebih dari itu, pada APBD 2015 pemerintah Kota Cimahi telah mengalokasikan dana APBD lebih dari 5\% untuk sektor sanitasi.

Secara nyata, SSK periode 2011-2015 telah membawa perubahan pada bidang air limbah, persampahan dan drainase. Pada bidang air limbah, tingkat pengelolaan air limbah domestik secara on site mencapai $61,82 \%$, serta dengan sistem komunal sebesar 0,24\%. Pada bidang persampahan kuantitas timbulan sampah yang dapat dikelola baru mencapai 55\% dan pada bidang drainase terdapat 42 titik genangan. Tentunya data tersebut akan menjadi base line pada 
perbaikan kondisi sanitasi pada SSK yang dimuktahirkan. Selengkapnya informasi pada uraian tersebut dapat dilihat pada tabel.

\section{Kondisi Sanitasi Kota Cimahi dan Target Pembangunan Sanitasi Kota}

Cimahi 2015

\begin{tabular}{|c|c|c|}
\hline Bidang & Kondisi Sanitasi & Target Pembangunan Sanitasi \\
\hline Air Limbah & $\begin{array}{l}\text { Tingkat pelayanan } \\
\text { pengelolaan air } \\
\text { limbah domestik baru } \\
\text { mencapai } \\
63,14 \% \text { dimana sistem } \\
\text { on site sebesar } \\
61,82 \% \text { dan sistem off } \\
\text { site skala } \\
\text { komunal sebesar } 0,24 \% \text {. }\end{array}$ & $\begin{array}{l}\text { Cakupan layanan air limbah domestic sebesar } 75 \% \text {. } \\
\text { PHBS: } 75 \% \text { masyarakat } \\
\text { berperilaku sehat, } 80 \% \text { tatanan keluarga sehat, } 80 \% \\
\text { keluarga berlingkungan sehat, } 80 \% \text { keluarga berumah } \\
\text { sehat, } 80 \% \text { keluarga menggunakan air bersih, } 85 \% \\
\text { keluarga gunakan jamban sehat, } 80 \% \text { sekolah sehat, } \\
\text { dan } 80 \% \text { kelurahan sehat. }\end{array}$ \\
\hline Persampahan & $\begin{array}{l}\text { Tingkat pelayanan } \\
\text { persampahan } \\
\text { melalui pembuangan ke } \\
\text { TPPAS sebesar } \\
18 \% \text {, pengelolaan } 3 \mathrm{R} \\
\text { sebesar } 27,5 \% \text {, } \\
\text { omposting plan sebesar } \\
9,2 \% \text { dan } \\
\text { biogas sebesar } 0,3 \% \text {. } \\
\text { Jumlah sampah } \\
\text { yang terkelola baru } \\
\text { sebesar } 55 \% \text {. }\end{array}$ & $\begin{array}{l}\text { Meningkatkan cakupan pelayanan sampah } \\
\text { menjadi sebesar } 75 \%\end{array}$ \\
\hline $\begin{array}{l}\text { Drainase } \\
\text { Lingkungan }\end{array}$ & $\begin{array}{l}\text { Masih terdapat } 42 \text { titik } \\
\text { genangan air di Kota } \\
\text { Cimahi, dimana } 12 \\
\text { lokasi di Cimahi } \\
\text { Selatan, } 13 \text { lokasi di } \\
\text { Cimahi Utara, dan } \\
17 \text { lokasi di Cimahi } \\
\text { Tengah }\end{array}$ & Bebas dari genangan banjir Tahun 2015 \\
\hline
\end{tabular}

Sumber : Berbagai sumber 2020

Kota Cimahi, dengan SSK sebelumnya telah berhasil meningkatkan akses pengelolaan air limbah domestik mencapai $63,14 \%$, sedikit di atas rata-rata nasional yang mencapai $60,5 \%$ di tahun 2014 . Tentunya fakta tersebut menjadi modal nyata yang berharga bagi Kota Cimahi untuk mendukung program pemerintah dalam bidang sanitasi. Demikian pula dengan sektor persampahan dan drainase, pemerintah Kota Cimahi terus berusaha mensinergikan penyelenggaraan air minum dan sanitasi yang dilakukan di tingkat nasional, provinsi, kabupaten/ kota, dan masyrakat. Namun target di tahun 2019 dengan 100\% perbaikan sanitasi tidak tercapai sehingga pemeritah pusat mendorong Pemerintah Daerah untuk 
meningkatkan pembangunan sarana bidang penyehatan lingkungan permukiman melalui Program Hibah Australia-Indonesia untuk Pembangunan Sanitasi/Program Australia-Indonesia Infrastructure Grants for Sanitation (SAIIG).

Melalui program ini Pemerintah memberikan dana hibah untuk kabupaten/kota yang telah melaksanakan kegiatan sektor tersebut dengan menggunakan dana APBD pada tahun anggaran berjalan. Melalui Indonesia Infrastructure Grants for Sanitation (SAIIG) Kota Cimahi dapat melanjutkan program pengelolaan sanitasi secara komprehensif, berkelanjutan dan partisipatif untuk mengimplementasikan perencanaan dan pembangunan sanitasi dalam rangka mencapai target-target pencapaian layanan sektor sanitasi kota Cimahi.

\section{PEMBAHASAN}

Secara geografis wilayah Kota Cimahi merupakan lembah cekungan yang melandai dari utara ke selatan, dengan ketinggian di bagian utara $\pm 1,040$ meter dpl yang merupakan lereng Gunung Burangrang dan Gunung Tangkuban Perahu dan di bagian selatan sekitar \pm 685 meter dpl yang mengarah ke Sungai Citarum. Berdasarkan Undang-Undang Nomor 9 Tahun 2001, Kota Cimahi memiliki luas wilayah 4.025,73 ha, dengan posisi geografis Kota Cimahi terletak pada koordinat 107031'15',- 107034'30', Bujur Timur dan 6050'00'-6056'00', 6056'00', Lintang Selatan

Berdasarkan UU No. 9 Tahun 2001 tentang pembentukan Kota Cimahi, luas Kota Cimahi secara administratif tercatat seluas 4025,73 Ha, dimana wilayah kota ini terbagi atas 3 kecamatan dan 15 kelurahan, yaitu: Kecamatan Cimahi Utara yang meliputi 4 Kelurahan, Kecamatan Cimahi Tengah yang meliputi 6 Kelurahan, dan Kecamatan Cimahi Selatan yang meliputi 5 Kelurahan. Jumlah penduduk kota Cimahi dalam lima tahun terus mengalami peningkatan. Kecamatan Cimahi selatan merupakan kecamatan dengan jumlah penduduk tertinggi pada tahun 2018, penduduk di wilayah ini mencapai 630.193 jiwa. Kecamatan Cimahi Utara memiliki jumlah penduduk tertinggi ke-2 dengan jumlah penduduk 185.328 jiwa. Peningkatan jumlah penduduk mengakibatkan 
semakin beragamnya pola dan tingkat konsumsi untuk kebutuhan dasar serta kebutuhan lainnya dan tentu nya hal ini akan berakibat pada pengelolaan sanitasi.

Berdasarkan data series sebelumnya, serta dengan mempertimbangkan RTRW Kota Cimahi, maka tingkat pertumbuhan penduduk pada setiap kelurahan di Kota Cimahi adalah konstan pada setiap kelurahan. Kepadatan penduduk merupakan salah satu parameter penting dalam penentuan teknis pengelolaan sanitasi di Kota Cimahi. Sebagai contoh teknis pengelolaan air buangan domestik serta pengolahan dan tranportasi sampah, akan ditentukan dengan sangat memperhatikan kepadatan penduduk dan ketersediaan lahan. Semakin padat penduduk, maka ketersediaan lahan yang dibutuhkan untuk pengolahan limbah dan sampah akan semakin sulit di dapatkan. Selanjutnya semakin padat penduduk, maka kerentanan pencemaran akan semakin meningkat, dan pada akhirnya semakin padat penduduk maka penularan penyakit akan semakin mudah.

Badan Pusat Statistik, mendefinisikan kemiskinan sebagai ketidakmampuan memenuhi standar minimum kebutuhan dasar yang meliputi kebutuhan makan maupun non makan. Penduduk Miskin adalah penduduk yang memiliki rata-rata pengeluaran perkapita perbulan dibawah garis kemiskinan. Garis Kemiskinan (GK) merupakan penjumlahan dari Garis Kemiskinan Makanan (GKM) dan Garis Kemiskinan Non Makanan (GKNM). Penduduk yang memiliki rata-rata pengeluaran perkapita per bulan dibawah Garis Kemiskinan dikategorikan sebagai penduduk miskin.

Peningkatan jumlah penduduk secara tidak langsung dapat meningkatkan tingkat persaingan baik pada saat ini maupun yang akan datang. Kompetisi akan semakin ketat dan lapangan kerja yang tersedia tidak mampu menampung sumber daya manusia yang ada. Akibatnya sumber daya manusia yang tidak mampu berkompetisi akan tersisihkan. Kemiskinan yang terjadi membawa dampak baru pada lingkungan dan sosial dimana lingkungan kumuh akan muncul serta meningkatkan probabilitas angka kriminalitas. Dari banyak keterkaitan di atas maka, disini akan fokus kepada keterkaitan kemiskinan dan kondisi sanitasi.

Minimnya pendapatan masyarakat akan berdampak kepada rendahnya kesadaran masyarakat terhadap pembangunan bidang sanitasi. Kemiskinan akan 
mendorong mereka untuk fokus kepada pemenuhan kebutuhan dasar, dan tidak memprioritaskan fasilitas sanitasi yang layak (Rizki dan Saleh, 2007). Sanitasi yang tidak layak seperti BABS, membuang sampah dengan prosedur yang kurang tepat,merupakan contoh tindakan yang dapat menimbulkan dampak negatif terhadap lingkungan. Sanitasi yang tidak memadai berdampak negatif bagi kesehatan dan ekonomi, WHO menyatakan sanitasi, akses air bersih, dan layanan kebersihan yang memadai berperan penting mencegah penyakit wabah sekaligus mengendalikan infeksi. Tabel berikut mensajikan data mengenai jumlah KK miskin kota Cimahi pada tahun 2018.

Jumlah Keluarga miskin kota Cimahi tercatat pada data tahun 2018 yakni berjumlah total $12.940 \mathrm{KK}$. Dari tiga kecamatan di Kota Cimahi, kecamatan Cimahi Selatan menjadi kecamatan dengan jumlah Keluarga miskin tertinggi yakni berjumlah $2.512 \mathrm{KK}$. Sedangkan untuk kecamatan dengan jumlah keluarga miskin terendah ada pada kecamtan Cimahi Tengah yakni dengan jumlah 1.941 KK. Menurut data di atas, diketahui bahwa angka kemiskinan kota Cimahi mendekati $10 \%$, dan masih tergolong tinggi, karena data BPS menunjukan hingga september 2013 angka kemiskinan di Kota rata-rata di Indonesia adalah 8\% dari total penduduk Kota.

Jumlah Indikasi kebutuhan biaya pengembangan sanitasi untuk 5 (lima) tahun ke depan, serta besaran biaya sanitasi didasarkan program pengembangan sektor sanitasi yang telah disusun oleh Kota Cimahi dalam RPIJM. Kebutuhan biaya ini menitikberatkan pada jenis program yang merupakan investasi sanitasi di kota Cimahi.

Ada 3 hal yang berkaitan dengan rencana pendanaan Kota Cimahi dan kota-kota lain yang sedang menyusun dokumen MP pada umumnya, dalam mendanai program dan kegiatan sanitasinya, yaitu availability sumber pendanaan, staging (pentahapan) program dan packaging (pemaketan) program, yang perlu dipertimbangkan sebagai dasar dari strategi pendanaan bagi pelaksanaan MP. Strategi pendanaan yang dimaksud agar target MP dapat tercapai secara efektif dan efisisen. Lebih dari itu, pembiayaan sanitasi tidak hanya berasal dari APBD Kota Cimahi namun dapat berasal dari APBD Provinsi Jawa Barat, bahkan berasal 
dari APBN yang dikelola oleh satuan kerja pada masing-masing sub sektor dan program.

Australia-Indonesia Infrastructure Grants for Sanitation (SAIIG). Di Kota Cimahi sendiri, instansi teknis yang menagani permasalahan air limbah domestik dan sampah adalah Dinas pertamanan dan Kebersihan (DPK) Kota Cimahi, sementara untuk drainase pemukiman ditangani oleh Dinas PU Detail besaran biaya pengembangan sanitasi dapat dilihat pada tabel-tabel berikut ini:

\section{Grafik Ringkasan Indikasi Kebutuhan Biaya Pengembagan Sanitasi}

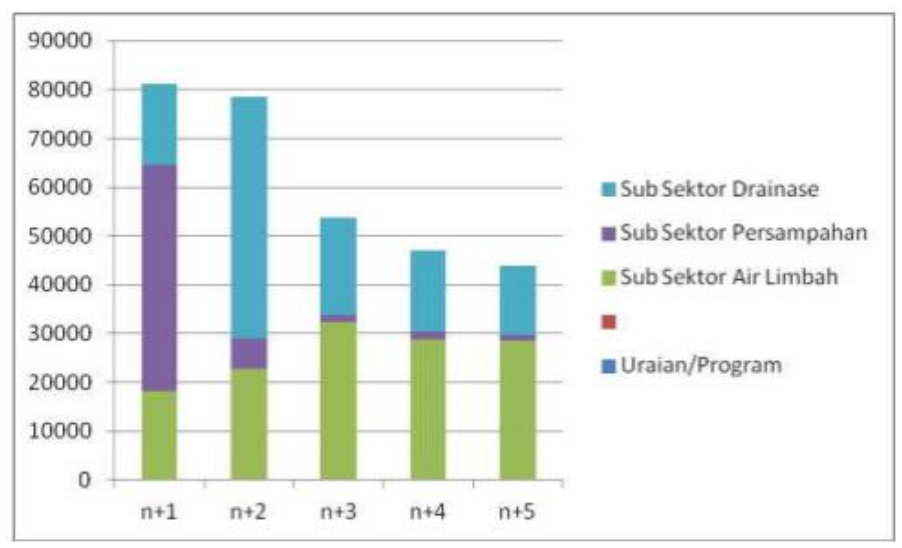

Kota Cimahi memiliki prioritas pendanaan untuk sub sektor air limbah, disusul oleh drainase lingkungan dan persampahan. Kota Cimahi pada tahun 2020 akan menggunakan dana penerusan yang bersumber dari APBN dan program Australia-Indonesia Infrastructure Grants for Sanitation (SAIIG) untuk sepenuhnya membiayai pembangunan infrastruktur air limbah khususnya IPAL Kawasan dengan total anggaran Rp 26.728.000.000,00. Sedangkan untuk sub sektor persampahan, fasilitas dari pemerintah daerah akan digunakan untuk peningkatan sarana dan prasarana persampahan di kota Cimahi seperti pembangunan TPS, pengadaan kendaraan pengangkut sampah, pembangungan transfer depo. pembanguna ITF pengadaan gerobak sampah, peningkatan pengelolaan sampah dengan sistem 3R (Reuse,Reduce, Recycle) melalui Pengolahan Sampah Organik dan Anorganik dari 37\% menjadi 55\% dan tersedianya masterplan pengelolaan sampah kota pada tahun 2020. Dana yang berasal dari APBD Kota, APBD Provinsi dan APBN setelah di akumulasikan dari 
tahun 2014-2018 untuk sektor persampahan adalah sebesar Rp. 57.012.000.000,00.

Untuk sub sektor drainase secara umum Kota Cimahi, dana yang berasal dari APBD Kota, APBD Provinsi dan APBN serta program Australia-Indonesia Infrastructure Grants for Sanitation (SAIIG) di akumulasikan dari tahun 20142020 sebesar Rp. 116.720.000.000,00. Dana tersebut digunakan untuk kegiatan program pembangunan saluran drainase/gorong-gorong, perencanaan pembangunan saluran drainase/gorong-gorong, program pengembangan pengelolaan dan konservasi sungai danau dan SDA lainnya, Pembangunan kolam/sumur retensi/biopori, pemeliharaan dan rehabilitasi embung dan bangunan penampung air lainnya, pembangunan saluran drainase sekunder dan rehabilitasi saluran drainase sekunder, program pengembangan dan pengelolaan jaringan irigasi, rawa dan jaringan pengairan lainnya.

Dari total kebutuhan pembangunan untuk subsektor air limbah pada tahun 2020 adalah sebesar Rp 1.060.800.000. Dana tersebut berasal dari PAGU DAK untuk pembangunan Sanitasi Lingkungan Berbasis Masyarakat (SLBM) Septiktan Komunal /MCK Plus. Lokasi Sanitasi Lingkungan Berbasis Masyarakat (SLBM) Septiktan Komunal /MCK Plus berada di Kota Cimahi.

Beberapa indikator yang dibutuhkan untuk menentukan sistem pentahapan sanitasi dan sekaligus menentukan zona sanitasi adalah: kondisi tanah, kepadatan penduduk, apakah area termasuk tata guna lahan seperti Central Business District (CBD) atau bukan pada saat ini maupun yang akan datang (di Kota Cimahi istilah CBD diganti dengan Pusat Pelayanan Kota, merujuk pada draft RT/RW terbaru), apakah area tersebut termasuk area beresiko sedang/ tinggi/ sangat tinggi dan kondisi sub soil. Area yang digunakan sebagai dasar penentuan adalah kelurahan. Tiap kelurahan diseleksi berdasarkan indikator-indikator dalam diagram di atas sehingga nantinya akan muncul pentahapan sistem air limbah domestik dari tiap kelurahan tersebut. Pentahapan sistem tersebut terdiri dari lima pentahapan yakni:

1. Sistem terpusat jangka panjang,

2. Sistem terpusat jangka menengah,

3. Sistem setempat berbasis rumah tangga, 
4. Sistem setempat (stbm, mck+) dengan potensi peningkatan ke sistem setempat berbasis rumah tangga dan

5. Sistem setempat berbasis rumah tangga dan/atau masyarakat dengan potensi peningkatan ke sistem terpusat jangka panjang.

Berikut adalah beberapa indikator untuk menetapkan zona dan petahapan sistem air limbah domestik :

1. Kepadatan penduduk proyeksi untuk 5 tahun mendatang, dengan kategori yaitu:
a) Rural : di bawah 25 orang per ha.
b) Peri-urban : 25-100 orang per ha.
c) Urban low : 100-175 orang per ha.
d) Urban medium : 175-250 orang per ha.
e) Urban high: di atas 250 orang per ha.

2. Karakteristik fisik yakni kondisi tanah yang tidak sesuai. Data mengenai kondisi tersebut didapatkan dari kondisi erodibilitas, kerentanan gerakan tanah dan erosi (Laporan Fakta dan Analisa Penyusunan Revisi Rencana Tata Ruang dan Wilayah Kota Cimahi Tahun Anggaran 2019). Penjelasannya adalah sebagai berikut :

a) Kondisi Erodibilitas

b) Kerentanan Gerakan

3. Erosi Jenis pemanfaatan lahan, yakni Pusat Pelayanan Kota (PPK) pada masa kini dan masa yang akan datang.

a) Area Beresiko (Sedang/ Tinggi/ sangat tinggi)

b) Kondisi Sub Soil

Berdasarkan pemaparan diatas di atas maka zona dan pentahapan sistem air limbah domestik di Kota Cimahi dapat ditetapkan sebagai berikut: 
Penentuan Zona Sanitasi Dan Pentahapan Sistem Air Limbah Domestik di Kota Cimahi

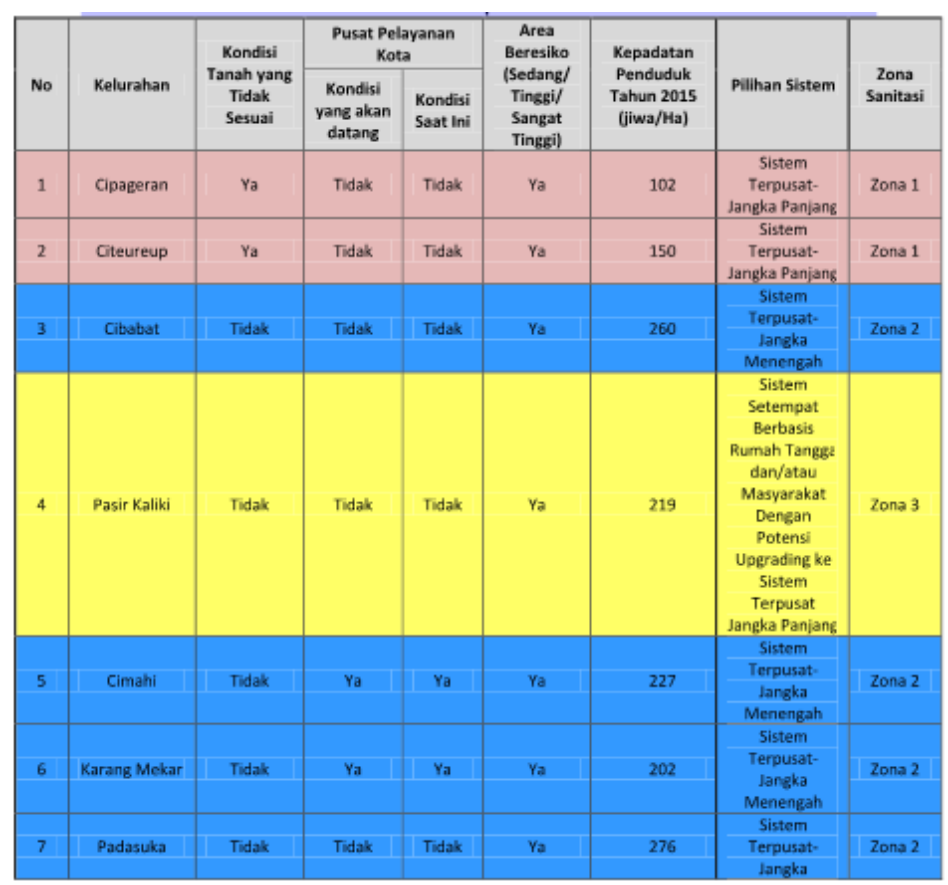

Bagan pada gambar di atas menginformasikan indikator yang dibutuhkan untuk menentukan zona dan pentahapan sistem persampahan adalah kepadatan penduduk dan apakah area termasuk Central Business District (CBD) atau bukan pada masa yang akan datang (di Kota Cimahi istilah CBD diganti dengan Pusat Pelayanan Kota, merujuk pada draft RT/RW terbaru). Hal lain yang perlu di perhatikan pada penetapan zona pengembangan adalah tahapan persentase dari tahap pengembangan persampahan Kota seperti terlihat pada tabel di bawah:

\section{Tahapan Pengembangan Persampahan Kota Cimahi}

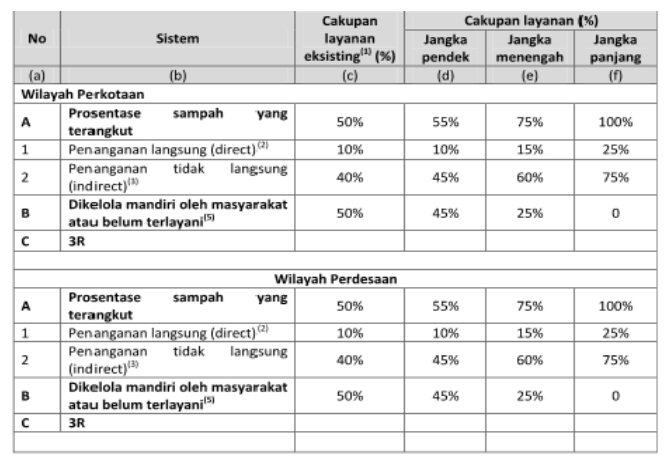


Tabel di atas menginformasikan prosentase sampah terangkut pada tahun 2020 di Kota Cimahi adalah 50\% dari timbulan sampah yang ada, artinya 50\% sampah dikelola secara mandiri oleh masyarakat. Dua variabel ini akan mendapat perlakuan yang berbeda, dimana prosentase sampah yang terangkut akan di tingkatkan secara bertahap hingga mencapai $100 \%$ di tahun 2021, sementara sampah yang dikelola mandiri oleh masyarakat akan di kurangi hingga nihil (0\%) pada tahun 2020. Target ini sesuai dengan visi sanitasi Kota Cimahi, yang mendukung universal akses. Selanjutnya, pengembangan di dasarkan pada tingkat kelurahan.

Dalam menciptakan sitem drainase yang baik, maka diperlukan perawatan sarana dan prasarana drainase agar drainase yang ada dapat berfungsi maksimal dan sebagaimana mestinya. Data mengenai kondisi sarana dan prasarana drainase kota Cimahi disajikan pada tabel.

\section{Kondisi Sarana dan Prasarana Drainase Perkotaan Kota Cimahi}

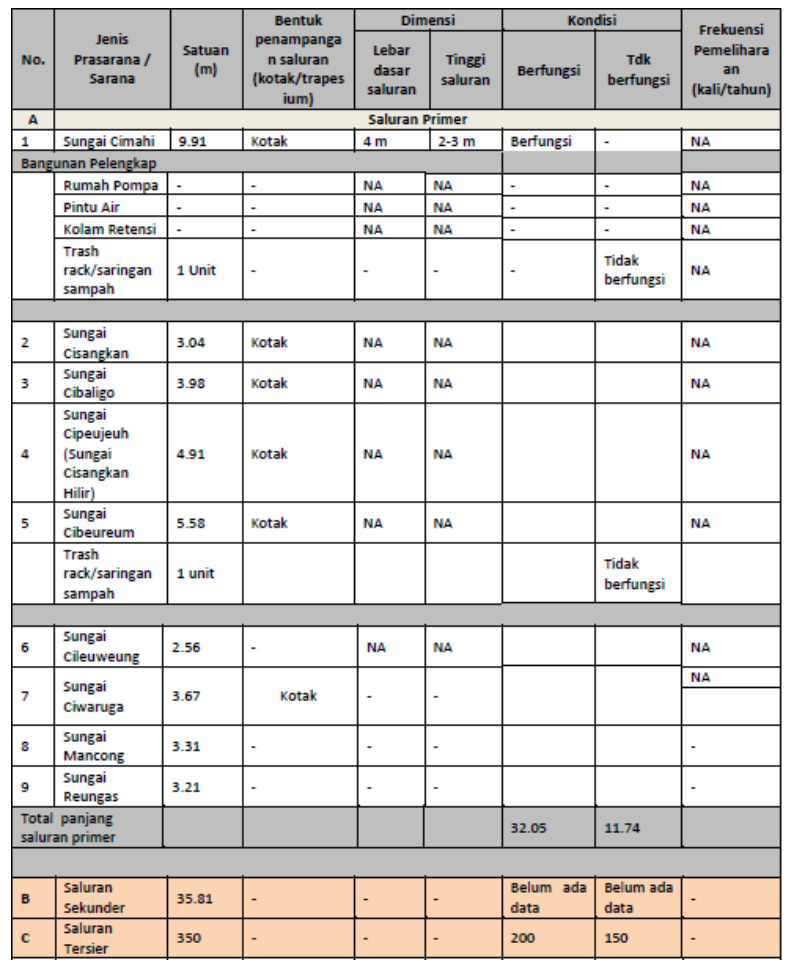

Sumber : Dinas pekerjaan umum Kota Cimahi tahun 2010

Keterangan: NA = Not Available (tidak tersedia) data. 
Penduduk Kota Cimahi yang setiap tahunnya bertambah tentunya akan berakibat terhadap perubahan tata guna dan tutupan lahan. Tutupan lahan dengan perkerasan semakin meningkat karena peningkatan jumlah pemukiman yang cenderung mengurangi infiltrasi air hujan atau meningkatkan limpasan permukaan (run off). Perubahan sifat dan karakteristik aliran permukiman ini tentunya harus diikuti dengan penyesuaian prasarana drainase. Banyaknya konversi lahan yang tidak diikuti dengan penanganan drainase yang tepat dan berwawasan lingkungan telah menimbulkan banyak masalah belakangan ini.

Persoalan mengenai air limbah domestik memang sering terlupakan. Hal tersebut disebabkan lapisan masyarakat tidak memikirkan saluran sanitasi dan penampungan limbah mereka secara baik dan benar. Dalam hal tersebut pemerintah pusat mempunyai upaya untuk mendorong pemerintah daerah guna meningkatkan pembangunan sarana dalam bidang bidang penyehatan lingkungan permukiman melalui Program Hibah Australia-Indonesia untuk pembangunan Sanitasi/Program Australia-Indonesia Infrastructure Grants for Sanitation (sAIIG).

Seperti yang sudah dijelaskan di atas bahwa program ini memberikan dana hibah untuk kabupaten/kota yang telah melaksanakan kegiatan sektor tersebut dengan menggunakan APBD pada tahun anggaran berjalan. Oleh karena itu program program ini merupakan langkah strategis yang tepat untuk diambil. Sampai dengan saat ini pemerintah kota Cimahi telah membangun paling sedikit 9.000 saluran sanitasi. Selain dari pada itu, Saat ini pemerintah kota cimahi tengah merampungkan pembangun sanitasi komunal untuk 400 rumah di dua rukun warga (RW), di Kecamatan Cibabat.

Oleh karenanya program sanitasi ini bertujuan untuk meningkatkan investasi pemda di sektor sanitasi. Program ini juga bertujuan meningkatkan kesadaran masyarakat pada sanitasi. Dengan hadirnya program ini telah memberikan dampak yang cukup signifikan dimana masyarakat mulai menyadari arti pentingnya sanitasi dan pengelolaan sampah secara baik dan benar dan masyarakat sudah mulai mempedomani implementasi program ini. 


\section{KESIMPULAN}

Berdasarkan pemaparan di atas jelas bahwa pengambilan kebijakan dalam implementasi program sanitasi Australia Indonesia Infrastructure Grants for Sanitation/sAIIG di Kota Cimahi pada tahun 2020-2021 dengan berbagai dinamikanya, telah memberikan dampak yang cukup signifikan bagi pemerintah dan masyarakat secara umum untuk kualitas hidup dan lingkungan yang lebih baik.

\section{DAFTAR PUSTAKA}

Badan Pusat Statistik. 2018. Kependudukan Kota Cimahi. Cimahi.

BAPPEDA Kota Ciamahi Tahun 2020. Pemangku Kepentingan dalam Pembangunan dan Pengelolaan Sanitasi sub Sektor Persampahan Kota Cimahi.

Bappeda Kota Cimahi Tahun 2014. Pembangunan dan Pengelolaan Sanitasi sub Sektor Drainase Kota Cimahi 2013.

Bhimo Rizki dan Samsubar Saleh, 2007. Ruang Lingkup Kajian. Kajian penelitian tentang aksesibilitas sanitasi di Provinsi Jawa Tengah. Universitas Diponegoro.

Creswell, John W, 2010. "Research Design Pendekatan Kualitatif, Kuantitatif dan Campuran”, Yogyakarta. Pustaka Pelajar.

David Ray. 2012. Jurnal Prakarsa Infrastruktur Indonesia. Pendekatan INDII Terhadap Hibah Berbasis Hasil. Edisi 12. Jakarta.

Dinas Kebersihan dan Pertamanan Kota Cimahi, Tahun 2020. Sarana dan Prasarana Pengelolaan Persampahan Kota Cimahi Tahun 2020. Cimahi.

Dinas pekerjaan umum kota cimahi tahun 2010. Sarana dan Prasarana Drainase Perkotaan Kota Cimahi.

https://sites.google.com/site/kelolakualitas/Diagram-Fishbone

Irma Setiano. 2012. Jurnal Prakarsa Infrastruktur Indonesia. Kota Surabaya dengan Global Partnership on Output-Based Aid (GPOBA) dalam melakukan peningkatan pelayanan ketersediaan air bersih bagi masyarakat miskin perkotaan. Jakarta. 
Kementrian Pekerjaan Umum Bidang Cipta Karya tahun 2020. Sistem drainase perkotaan. Jakarta.

Liang Gie. Thoha Miftah. 1978. Unsur-unsur Administrasi. Yogyakarta : Kencana.

Mardalis. 1995. Metode Penelitian Suatu Pendekatan Proposal, Jakarta: Bumi Aksara.

Moduto. 2000. Penyaluran Air Buangan (PAB). Volume II. ITB.

Sabar. 2005.Pengantar Metodologi Penelitian. FKIP: Universitas Muria. Kudus.

Sudarwan Danim, 2002. Menjadi Peneliti Kualitatif, Bandung : Pustaka Setia.

UU No. 9 Tahun 2001 tentang Pembentukan Kota Cimahi. 